\title{
Metformin Does Not Affect Clinically Relevant Outcomes in Patients with Idiopathic Pulmonary Fibrosis
}

\author{
Paolo Spagnolo ${ }^{a}$ Michael Kreuter ${ }^{b}$ Toby M. Maher, d Wim Wuyts ${ }^{\mathrm{e}}$ \\ Francesco Bonella $^{f}$ Tamera J. Corte $^{g}$ Stefan Kopf $^{\text {h }}$ Derek Weycker ${ }^{i}$ \\ Klaus-Uwe Kirchgaessler ${ }^{j} \quad$ Christopher J. Ryerson ${ }^{k}$ \\ a Section of Respiratory Diseases, Department of Cardiac, Thoracic and Vascular Sciences, University of Padova,

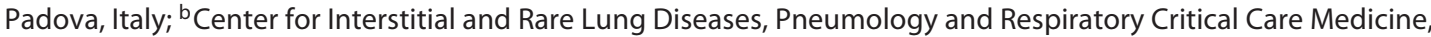 \\ Thoraxklinik, University of Heidelberg, Member of the German Center for Lung Research, Heidelberg, Germany; \\ 'Interstitial Lung Disease Unit, Royal Brompton Hospital, London, UK; ${ }^{d}$ Fibrosis Research Group, National Heart and \\ Lung Institute, Imperial College London, London, UK; ${ }^{e}$ Department of Respiratory Medicine, University Hospitals \\ Leuven, Leuven, Belgium; Interstitial and Rare Lung Disease Unit, Ruhrlandklinik, University of Duisburg-Essen, \\ Essen, Germany; ${ }^{9}$ Department of Respiratory Medicine, Royal Prince Alfred Hospital and University of Sydney, \\ Sydney, NSW, Australia; ${ }^{\mathrm{h}}$ Department of Endocrinology, Metabolism and Clinical Chemistry, Heidelberg University \\ Hospital, Heidelberg, Germany; 'Policy Analysis Inc. (PAI), Brookline, MA, USA; 'F. Hoffmann-La Roche, Ltd., Basel, \\ Switzerland; ${ }^{2}$ Department of Medicine, University of British Columbia, Vancouver, BC, Canada
}

\section{For editorial comment see p. 305}

\section{Keywords}

Diabetes mellitus · Hyperglycemia · Idiopathic pulmonary fibrosis - Metformin · Post hoc analysis

\begin{abstract}
Background: Diabetes mellitus is a possible risk factor for the development of idiopathic pulmonary fibrosis (IPF), yet the effect of antidiabetic therapy on the course of IPF is unknown. Objectives: This post hoc analysis assessed the effect of metformin on clinically relevant outcomes in patients with IPF. Methods: For the primary analysis, patients randomized to placebo ( $n=624$ ) in 3 phase 3 , double-blind, controlled trials of pirfenidone (CAPACITY [NCT00287716 and NCT00287729]; ASCEND [NCT01366209]) were categorized by baseline metformin use. The primary outcome was disease progression (forced vital capacity [FVC] decline
\end{abstract}

\section{KARGER}

(c) 2018 S. Karger AG, Basel

E-Mail karger@karger.com

www.karger.com/res $\geq 10 \%$, 6-min walking distance [6MWD] decline $\geq 50 \mathrm{~m}$, or death). Other outcomes included mortality, hospitalization, FVC decline ( $\geq 10$ and $\geq 5 \%$ ), and 6MWD decline. Outcomes were also assessed in patients with diabetes and/or hyperglycemia (impaired glucose tolerance [IGT] and diabetes population [IGT-diabetes population]) and all patients included in the 3 studies (intention-to-treat [ITT] population). Results: Overall, 71 (11.4\%) patients were metformin users and $553(88.6 \%)$ were nonmetformin users. Baseline data were similar between groups, except for a higher percentage of males (84.5 vs. $73.2 \%$ ) and a history of diabetes (98.6 vs. $11.6 \%$ ) in metformin users versus nonmetformin users. The unadjusted 1-year analyses demonstrated no significant differences in disease progression or other outcomes. A higher proportion of metformin users compared with nonmetformin users had a relative FVC decline of $\geq 5 \%$ ( 63.4 vs. $50.6 \%, p=0.043)$. Results were similar for the IGT-diabetes 
population and for the ITT population. Multivariable analyses yielded similar results. Conclusions: Metformin has no effect on clinically relevant outcomes in patients with IPF.

(c) 2018 S. Karger AG, Basel

\section{Introduction}

Idiopathic pulmonary fibrosis (IPF) is a progressive, irreversible, ultimately fatal, fibrosing lung disease $[1,2]$ that is associated with a poor prognosis [3], reduced health-related quality of life $[4,5]$, and a number of debilitating symptoms, including shortness of breath, cough, and exercise limitation $[5,6]$. Antifibrotic treatment reduces disease progression in patients with IPF, and 2 drugs, pirfenidone and nintedanib, are approved in the European Union and United States for the treatment of IPF based on data from large randomized clinical trials [7-13]. Despite the approval of pirfenidone and nintedanib, IPF will ultimately progress in all patients and, as a result, more effective treatments are still required [14].

The etiology and pathophysiology of IPF are not yet fully understood, but evidence suggests that comorbid conditions influence the clinical course of the disease. For example, comorbid lung cancer and arteriosclerosis negatively impact survival in IPF, whereas gastroesophageal reflux disease and diastolic dysfunction have been reported to have a possible positive effect [15]. Diabetes mellitus is another common comorbidity in IPF, occurring in $10-33 \%$ of patients [16]. Diabetes has been considered as a possible risk factor for the development or progression of IPF $[17,18]$; there is a significant association between the etiology of IPF and factors relating to diabetes, the strongest being an increased risk of IPF in patients treated with insulin [19]. However, it should be noted that steroids, which were commonly used as a treatment for IPF before the introduction of antifibrotic agents, could have contributed to the development of diabetes in patients with IPF and may account, in part, for a potential link between IPF and diabetes [20]. Interestingly, recent metabolomic data have linked alterations in glucose metabolic pathways to structural remodeling of the lungs in patients with IPF [21], providing a potential mechanism by which diabetes could contribute to the pathogenesis of IPF.

Metformin is a commonly used oral antidiabetic medication with a wide range of effects on cellular biology [22]. Preclinical studies have suggested that metformin has antifibrotic and anti-inflammatory effects [23-25]. Metformin has been found to attenuate lung fibrosis by inhibiting transforming growth factor-beta (TGF- $\beta$ ) via adenosine monophosphate-activated protein kinase (AMPK) activation $[26,27]$.

Given that many patients with IPF have comorbid diabetes, it is important to understand the effects of antidiabetic medication on the clinical course of IPF. The potential antifibrotic and anti-inflammatory properties of metformin may be of particular benefit in patients with IPF. The aim of this post hoc analysis was to investigate the effect of metformin on mortality, disease progression, and other clinically relevant outcomes in patients with IPF enrolled in 3 large phase 3 clinical trials of pirfenidone, who were prescribed metformin for comorbid diabetes.

\section{Methods}

\section{Patients}

This post hoc analysis collected data from 3 phase 3 , controlled, double-blind trials of pirfenidone in IPF: CAPACITY (Studies 004 and 006; NCT00287716 and NCT00287729) [8] and ASCEND (Study 016; NCT01366209) [7].

Data were collated and pooled from the placebo arms of the 3 studies and categorized based on baseline metformin use (yes/no). These patients formed the primary analysis population (placebo population) for determining the effects of metformin in patients with IPF. From this population, a subgroup of patients with a history of diabetes mellitus and/or hyperglycemia was identified (impaired glucose tolerance [IGT] and diabetes population [IGT-diabetes population]) to investigate the effects of metformin in patients with IPF who also have diabetes. Following the definitions specified by the American Diabetes Association, patients with increased plasma glucose levels $(100-125 \mathrm{mg} / \mathrm{dL})$ were defined as patients with IGT, and patients with plasma glucose levels $\geq 126 \mathrm{mg} / \mathrm{dL}$ were defined as patients with diabetes [28]. Both groups were summarized as an IGT and diabetes population (IGTdiabetes population) and used for further analysis. Data were also collated for all patients included in the 3 studies (placebo and pirfenidone treatment arms; the intention-to-treat [ITT] population) to compare with the placebo group in order to confirm any observed effects of metformin in the wider IPF population.

Patient enrollment took place from April 2006 to November 2008 for CAPACITY and from July 2011 to January 2013 for ASCEND [7, 8]. Eligibility criteria for the CAPACITY and ASCEND studies have been described previously $[7,8]$. In brief, patients were aged between 40 and 80 years with a diagnosis of IPF confirmed by high-resolution computed tomography alone or highresolution computed tomography plus surgical lung biopsy, percent predicted forced vital capacity $(\mathrm{FVC}) \geq 50 \%$ (and $\leq 90 \%$ in ASCEND), percent predicted diffusing capacity of the lung for carbon monoxide (DLco) $\geq 35 \%$ ( $\geq 30$ and $\leq 90 \%$ in ASCEND), and 6-min walking distance $(6 \mathrm{MWD}) \geq 150 \mathrm{~m}$. Exclusion criteria included obstructive lung disease, clinically significant concomitant diseases, unstable IPF, active infection, and malignancy; patients with poorly controlled diabetes (glycated hemoglobin $\left[\mathrm{HbA}_{1 \mathrm{c}}\right]$ $>10 \%$ ) were also excluded in CAPACITY. CAPACITY and ASCEND were conducted in accordance with the International Con- 
ference on Harmonisation Guidelines, the Declaration of Helsinki, and the relevant local legal and regulatory requirements of the countries the trials were conducted in. Written, informed consent was obtained from patients before screening, and the study protocols were approved by the Institutional Review Board or Ethics Committee at each participating center.

\section{Assessments}

The primary composite outcome in this analysis was disease progression (defined as FVC decline $\geq 10 \%$, 6MWD decline $\geq 50 \mathrm{~m}$, or death from any cause). Other outcomes analyzed were all-cause and IPF-related mortality, all-cause hospitalization, infection-related hospitalization, absolute and relative FVC decline ( $\geq 10$ and $\geq 5 \%$ ), and $6 \mathrm{MWD}$ decline $\geq 50 \mathrm{~m}$. All outcomes were evaluated throughout 1 year.

\section{Statistical Analysis}

The primary analysis was study outcomes for metformin users compared with nonmetformin users in the placebo population. The subgroup analysis investigated outcomes in patients with diabetes or hyperglycemia at baseline based on medical history (IGT-diabetes population) comparing metformin users with nonmetformin users. The ITT analysis compared outcomes in all patients with IPF (placebo and treatment arms) stratified by metformin use.

Demographic and baseline characteristics, including age, sex, lung function, medical history, and cardiovascular risk factors, were compared between baseline users and nonusers of metformin using an independent samples $t$ test for continuous variables and a $\chi^{2}$ test for categorical variables. Unadjusted risks of binary study outcomes and changes from baseline in FVC and 6MWD were compared between baseline users and nonusers of metformin using an independent samples $t$ test or a $\chi^{2}$ test. In addition, binary study outcomes were compared within a bivariate and multivariable framework, using Cox proportional hazards models. Patients were censored at the time of loss to follow-up, at the time of lung transplantation, or at the end of the 1-year follow-up period, whichever occurred first.

In multivariable models, the impact of metformin use on study outcomes was adjusted for demographic and baseline characteristics, including age, sex, lung function, medical history, cardiovascular risk factors, infection history, and use of nonmetformin antidiabetic drugs. The presence of multicollinearity, hazards assumptions, and treating death as a competing risk were evaluated using published methods [29, 30].

SAS v.9.3 for Windows was used for all statistical analyses. Only observed data were employed (i.e., missing values were not imputed).

\section{Results}

\section{Patients}

In this post hoc analysis, 624 patients were included in the placebo population: $71(11.4 \%)$ were metformin users at baseline, and $553(88.6 \%)$ were nonmetformin users. The median (min., max.) duration of metformin use prior to inclusion in this post hoc analysis was $860(1,5,853)$ days. Baseline data were similar between groups, except for a higher percentage of males (84.5 vs. $73.2 \%$ ) and a higher prevalence of a history of diabetes (98.6 vs. $11.6 \%$ ) in metformin users than in nonmetformin users. Prior use of steroids was seen in $53.5 \%$ of metformin users and in $62.9 \%$ of nonmetformin users $(p=0.124)$. A total of $9.9 \%$ of metformin users and $11.9 \%$ of nonmetformin users were reported to have used acetylcysteine $(p=0.608$; Table 1). The mean (standard deviation) duration of follow-up was 352.7 (52.2) days in patients who received metformin and 342.9 (66.7) days in those who did not.

In total, 369 patients had a history of diabetes $(n=132)$ or hyperglycemia $(n=237)$ at baseline (IGT-diabetes population); $70(19.0 \%)$ were metformin users at baseline and $299(81.0 \%)$ were nonmetformin users. Baseline data were similar between groups, except for a higher prevalence of diabetes in metformin users $(70 / 70,100.0 \%)$ than in nonmetformin users $(62 / 299,20.7 \%)$. The mean (standard deviation) baseline glucose level was 141.14 (52.73) in metformin users and 111.34 (41.13) in nonmetformin users.

In addition, a total of 1,247 patients were included in the ITT population (placebo and treatment arms combined), assessed from both placebo and pirfenidone arms, and stratified by metformin use: 149 (11.9\%) were metformin users at baseline, and 1,098 (88.1\%) were nonmetformin users. Baseline data were similar between groups.

\section{Efficacy}

In unadjusted 1-year analyses of the placebo population, the incidence of disease progression (primary composite endpoint) was not statistically different between metformin users and nonmetformin users (40.8 vs. $40.9 \%$, $p=0.997$ ) (Table 2 ). There were also no statistically significant differences between groups for all-cause or IPFrelated mortality, all-cause hospitalization, 6MWD decline $\geq 50 \mathrm{~m}$, and infection-related hospitalization.

Categorical changes in FVC (relative and absolute decreases in FVC of $\geq 10 \%$ and an absolute decrease in FVC of $\geq 5 \%$ ) were not significantly different between the 2 analysis groups. However, there was a tendency for more patients in the metformin users group to have a relative $\geq 10 \%$ decline in FVC and an absolute $\geq 5 \%$ decline in FVC than in the nonmetformin users group $(p=0.055$ and $p=0.078$, respectively). The relative decrease in FVC of $\geq 5 \%$ was statistically significant and occurred in more patients in the metformin users group than in the nonmetformin users group (63.4 vs. $50.6 \%, p=0.043$ ) (Table 2).
Spagnolo et al. 
Table 1. Baseline characteristics by use of metformin (at time of randomization; placebo population)

\begin{tabular}{|c|c|c|c|}
\hline & Metformin users $(n=71)$ & Nonmetformin users $(n=553)$ & $p$ value \\
\hline \multicolumn{4}{|l|}{ Age, years } \\
\hline Mean (SD) & $66.5(6.2)$ & $67.2(7.7)$ & 0.349 \\
\hline Median & 65 & 68 & - \\
\hline IQR & 62,70 & 62,73 & - \\
\hline \multicolumn{4}{|l|}{ Sex, $n(\%)$} \\
\hline Male & $60(84.5)$ & $405(73.2)$ & 0.040 \\
\hline Female & $11(15.5)$ & $148(26.8)$ & - \\
\hline \multicolumn{4}{|l|}{ Physiological, mean (SD) } \\
\hline FVC, $\%$ predicted & $70.0(11.8)$ & $72.3(13.8)$ & 0.189 \\
\hline DLco, \% predicted & $45.6(10.7)$ & $45.6(11.2)$ & 0.982 \\
\hline $6 \mathrm{MWD}$ & $401.0(96.8)$ & $413.2(93.9)$ & 0.305 \\
\hline \multicolumn{4}{|l|}{ Dyspnea and HRQoL, mean (SD) } \\
\hline UCSD-SOBQ score & $34.2(25.9)$ & $35.0(21.0)$ & 0.815 \\
\hline \multicolumn{4}{|l|}{ Medical history } \\
\hline \multicolumn{4}{|l|}{ Comorbidities, $n$ (\%) } \\
\hline CVD & $18(25.4)$ & $149(26.9)$ & 0.775 \\
\hline CHD & $18(25.4)$ & $138(25.0)$ & 0.627 \\
\hline Cerebrovascular disease & $2(2.8)$ & $18(3.3)$ & 0.718 \\
\hline Heart failure & - & $5(0.9)$ & 0.393 \\
\hline CRF & $1(1.4)$ & $19(3.4)$ & 0.361 \\
\hline COPD & $2(2.8)$ & $20(3.6)$ & 0.731 \\
\hline Pulmonary hypertension & $1(1.4)$ & $18(3.3)$ & 0.394 \\
\hline Thyroid-related conditions ${ }^{\mathrm{b}}$ & $13(18.3)$ & $70(12.7)$ & 0.187 \\
\hline \multicolumn{4}{|l|}{ Cardiovascular risk factors, $n(\%)$} \\
\hline Hypertension & $44(62.0)$ & $296(53.5)$ & 0.179 \\
\hline Smoker (current/former) & $46(64.8)$ & $338(61.1)$ & 0.550 \\
\hline Diabetes & $70(98.6)$ & $64(11.6)$ & $<0.001$ \\
\hline Hypercholesterolemia & $40(56.3)$ & $255(46.1)$ & 0.104 \\
\hline Obesity $\left(\right.$ BMI $\left.>30 \mathrm{~kg} / \mathrm{m}^{2}\right)$ & $33(46.5)$ & $232(42.0)$ & 0.468 \\
\hline Infections (any) ${ }^{c}$ & $22(31.0)$ & $213(38.5)$ & 0.218 \\
\hline \multicolumn{4}{|l|}{ Medication history ${ }^{\mathrm{d}}$} \\
\hline Antidiabetic drugs, $n(\%)$ & $71(100.0)$ & $60(10.8)$ & $<0.001$ \\
\hline Dipeptidyl peptidase- 4 & $3(4.2)$ & $1(0.2)$ & $<0.001$ \\
\hline Glucosidase inhibitors & - & - & - \\
\hline Incretin mimetics & $1(1.4)$ & - & - \\
\hline Insulin & $6(8.5)$ & $21(3.8)$ & 0.070 \\
\hline Meglitinide & $3(4.2)$ & $2(0.4)$ & $<0.001$ \\
\hline Metformin & $71(100.0)$ & $11(2.0)$ & $<0.001$ \\
\hline Other & $1(1.4)$ & $1(0.2)$ & 0.085 \\
\hline Sulfonylurea & $19(26.8)$ & $30(5.4)$ & $<0.001$ \\
\hline Thiazolidinedione & $15(21.1)$ & $9(1.6)$ & $<0.001$ \\
\hline Number of antidiabetic drugs, $n$ (\%) & & & $<0.001$ \\
\hline 0 & - & $493(89.2)$ & - \\
\hline 1 & $28(39.4)$ & $34(6.1)$ & - \\
\hline 2 & $17(23.9)$ & $15(2.7)$ & - \\
\hline$\geq 3$ & $26(36.6)$ & $11(2.0)$ & - \\
\hline Prior use of steroids & $38(53.5)$ & $348(62.9)$ & 0.124 \\
\hline Prior use of statins & $47(66.2)$ & $274(49.6)$ & 0.008 \\
\hline Any use of NAC & $7(9.9)$ & 66 (11.9) & 0.608 \\
\hline
\end{tabular}

6MWD, 6-min walking distance; BMI, body mass index; CHD, coronary heart disease; $\mathrm{COPD}$, chronic obstructive pulmonary disease; CRF, chronic renal failure; CVD, cardiovascular disease; DLco, diffusing capacity of the lung for carbon monoxide; FVC, forced vital capacity; HRQoL, health-related quality of life; IQR, interquartile range; NAC, acetylcysteine; SD, standard deviation; UCSD-SOBQ, University of California San Diego Shortness of Breath Questionnaire. ${ }^{\text {a }}$ Out of a total maximum score of 120 , with higher score reflecting more severe shortness of breath. ${ }^{\mathrm{b}}$ Thyroid-related conditions include hyperparathyroid disorders, congenital thyroid disorders, hypothyroidism, hyperthyroidism and thyroid therapeutic procedures, and other specified disorders of thyroid for nonmetformin users. Thyroid-related conditions include hypothyroidism and other specified disorders of thyroid for metformin users. ${ }^{\mathrm{c}}$ Based on medical history file; timing of infection unknown. ${ }^{\mathrm{d}}$ Based on any evidence prior to randomization. Patients may not have been receiving these medications at baseline (e.g., 11 patients in the nonmetformin user group had previously taken metformin but were not receiving metformin at randomization). ${ }^{\mathrm{e}}$ Two-thirds of patients received NAC prior to baseline randomization and one-third of patients received NAC after baseline randomization. Information on drug dose is limited. 
Table 2. Unadjusted 1-year risk of study outcomes (placebo population) ${ }^{\mathrm{a}}$

\begin{tabular}{|c|c|c|c|}
\hline & $\begin{array}{l}\text { Metformin users }{ }^{\mathrm{b}} \\
(n=71)\end{array}$ & $\begin{array}{l}\text { Nonmetformin users }{ }^{\mathrm{b}} \\
(n=553)\end{array}$ & $\begin{array}{l}p \\
\text { value }\end{array}$ \\
\hline Primary composite outcome, $\%^{a, c}$ & 40.8 & 40.9 & 0.997 \\
\hline \multicolumn{4}{|l|}{ Mortality, \% } \\
\hline All-cause & 4.2 & 7.1 & 0.371 \\
\hline IPF-related & 2.8 & 4.7 & 0.470 \\
\hline \multicolumn{4}{|l|}{ FVC change (observed), $\%$} \\
\hline Absolute decrease $\geq 10 \%$ & 18.3 & 18.1 & 0.963 \\
\hline Relative decrease $\geq 10 \%$ & 39.4 & 28.4 & 0.055 \\
\hline Absolute decrease $\geq 5 \%$ & 50.7 & 39.8 & 0.078 \\
\hline Relative decrease $\geq 5 \%$ & 63.4 & 50.6 & 0.043 \\
\hline FVC change (observed), mean (SD) & $-5.9(6.1)$ & $-5.1(6.9)$ & 0.379 \\
\hline$n$ & 66 & 483 & \\
\hline FVC change (imputed), mean $(S D)^{d}$ & $-8.2(12.0)$ & $-9.5(17.1)$ & 0.538 \\
\hline \multicolumn{4}{|l|}{ Other outcomes, $\%$} \\
\hline 6MWD decrease (observed) $\geq 50 \mathrm{~m}$ & 29.6 & 26.2 & 0.547 \\
\hline Death or FVC decrease (absolute, observed) $\geq 10 \%$ & 21.1 & 23.9 & 0.608 \\
\hline Death or $6 \mathrm{MWD}$ decrease (observed) $\geq 50 \mathrm{~m}$ & 29.6 & 26.2 & 0.547 \\
\hline All-cause hospitalization & 21.1 & 18.8 & 0.639 \\
\hline Infection-related hospitalization & 7.0 & 6.3 & 0.817 \\
\hline Days of follow-up, mean (SD) & $352.7(52.2)$ & $342.9(66.7)$ & 0.232 \\
\hline \multicolumn{4}{|c|}{$\begin{array}{l}\text { 6MWD, 6-min walking distance; FVC, forced vital capacity; IPF, idiopathic pulmonary fibrosis; SD, standarc } \\
\text { deviation. }{ }^{\text {a }} \text { Primary composite outcome: FVC decrease } \geq 10 \%, 6 \mathrm{MWD} \text { decrease } \geq 50 \mathrm{~m} \text {, or death; only confirmec } \\
\text { cases included, defined as those for which follow-up assessment was repeated } \geq 6 \text { weeks following initial assess } \\
\text { ment and criteria for outcome were met. }{ }^{\mathrm{b}} \text { All patients were considered in the analyses, unless otherwise noted } \\
{ }^{c} \text { Only the first event was considered in the analyses. }{ }^{\mathrm{d}} \text { Missing data were not imputed except for the } 1 \text { measure } \\
\text { of FVC change, which was imputed using the clinical trial methodology. }\end{array}$} \\
\hline
\end{tabular}

Results were similar for the IGT-diabetes population (online suppl. Table 1; for all online suppl. material, see www.karger.com/doi/10.1159/000489668) and in the ITT population (online suppl. Table 2).

No significant differences between metformin users and nonmetformin users were observed in either the primary composite endpoint or all-cause mortality when compared within a bivariate and multivariable framework (Fig. 1). Results were largely similar in analyses of other endpoints (Fig. 1), the IGT-diabetes population (online suppl. Table 3), and the ITT population (online suppl. Table 4).

\section{Discussion}

In this post hoc analysis, metformin did not show any significant effect on clinically relevant outcomes in patients with IPF who received placebo in 3 phase 3 studies.
This was irrespective of a medical history of diabetes mellitus or hyperglycemia at baseline and was confirmed in the ITT population who received either pirfenidone or placebo. The only exception was in the placebo population, where there were tendencies for more patients in the metformin users group to have a relative $\geq 5 \%$ decline in FVC than in the nonmetformin users group $(p=0.043)$. The tendency for more metformin users to have a relative $\geq 10 \%$ decline in FVC and an absolute $\geq 5 \%$ decline in FVC when compared with the nonmetformin users did not quite achieve significance. Indeed, there was only one isolated statistical difference in this post hoc analysis, and it is possible that this was due to chance following multiple testing procedures and, therefore, does not necessarily imply clinical significance.

Although there are few studies on the association between diabetes and IPF, those that have been conducted suggest that the presence of diabetes has a negative effect on IPF, both in terms of development and progression of 


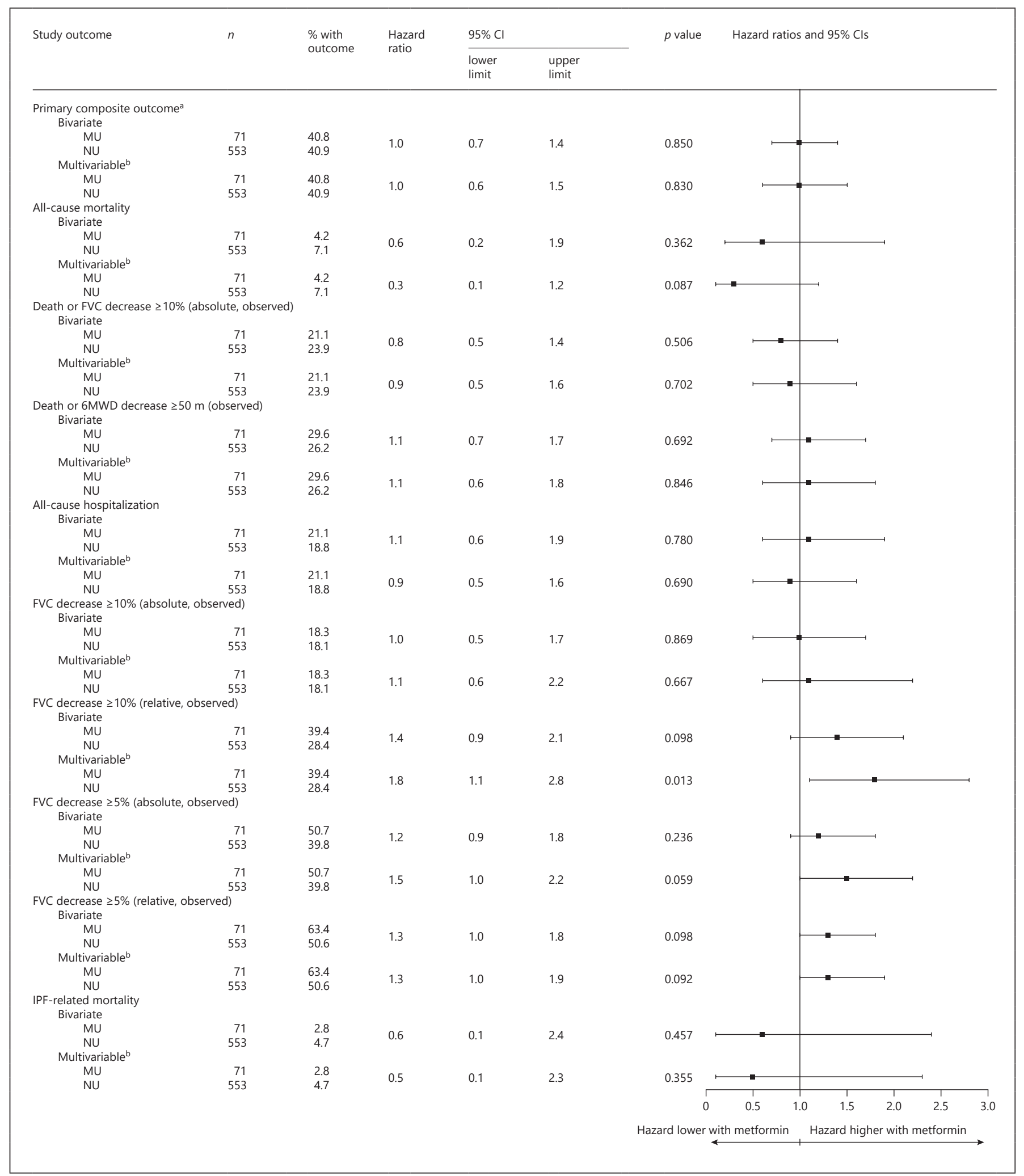

Fig. 1. Unadjusted and adjusted hazard ratios for all outcomes among metformin users and nonmetformin users. 6MWD, 6-min walking distance; CI, confidence interval; FVC, forced vital capacity; IPF, id- iopathic pulmonary fibrosis; $\mathrm{MU}$, metformin user; NU, nonmetformin user. ${ }^{\text {a }}$ FVC decrease $\geq 10 \%, 6 \mathrm{MWD}$ decrease $\geq 50 \mathrm{~m}$, or death; observed data only. ${ }^{\mathrm{b}}$ Adjusted for baseline characteristics. 
the disease. Previous studies have suggested that patients with diabetes have significant reductions in pulmonary function parameters (FVC, DLco, and forced expiratory volume in $1 \mathrm{~s}$ ) compared with nondiabetic controls and show histological changes and radiological changes (increased lung computed tomography score) associated with pulmonary fibrosis [18, 31, 32]. Additionally, patients with IPF and a history of diabetes were shown to have an increased risk of mortality [33].

The results of our analysis suggest that metformin has no effect on the clinical course of IPF. This contrasts somewhat with preclinical evidence from the literature, which suggests an antifibrotic, anti-inflammatory, and cell-protective effect of metformin in pulmonary fibrosis. Metformin was found to reduce radiological and histological signs of fibrosis, inflammatory cell infiltration, and alterations to alveolar structures, resulting in cellprotective effects from radiation-induced pulmonary injury in a mouse model [34]. In addition, 2 studies in bleomycin-induced lung fibrosis mouse models have shown that metformin exerts antifibrotic and anti-inflammatory effects $[26,35]$. The first study showed that metformin inhibited TGF- $\beta$-induced myofibroblast differentiation in lung fibroblasts via activation of AMPK [26]. In the other study, metformin was also shown to inhibit TGF- $\beta$ induced myofibroblast differentiation, thereby reducing the proportion of inflammatory cells in bronchoalveolar lavage fluid and reducing inflammation on histological examination of the lung tissue [35].

It is also possible that metformin exerts antifibrotic properties by ameliorating impaired autophagy (by activating AMPK, which in turn leads to enhanced autophagy and metabolic reprogramming, both of which have potential benefit in the context of aging-associated fibrosis) $[27,36,37]$, and as some studies have linked IPF with impaired autophagic processes $[38,39]$, we might expect metformin to have an effect on IPF outcomes. However, further research is needed to determine the link between autophagy and the molecular mechanisms of fibrogenesis in IPF.

Interestingly, a recent metabolomic study has found that glycolysis and gluconeogenesis are altered in the lungs of patients with IPF [21], providing a possible mechanism by which diabetes could promote the development of IPF. Antidiabetic drugs might, therefore, be expected to have a beneficial effect on outcomes in IPF via an effect on glucose metabolism; however, we could not confirm this in the current analysis with metformin. Metformin reduces blood glucose levels mainly by inhibiting hepatic gluconeogenesis and increasing insulin sensitiv- ity [40] and, therefore, may not target the pathways implicated in IPF pathogenesis by Zhao et al. [21]. Thus, further research is required to determine whether other antidiabetic drugs with different glucose metabolic targets could be beneficial for patients with IPF and diabetes.

This analysis had several limitations, including its post hoc nature and the small number of metformin users in CAPACITY and ASCEND. Furthermore, a formal power analysis was not conducted, and thus it is possible that the study was not powered adequately to address all questions of interest. Patients with advanced IPF and/or considerable comorbidities were excluded from CAPACITY and ASCEND, and the studies only included patients with FVC $\geq 50 \%$, DLco $\geq 35 \%$ ( $\geq 30 \%$ in ASCEND), and $6 \mathrm{MWD} \geq 150 \mathrm{~m}$ at baseline. Therefore, the results cannot necessarily be generalized to the broader population of patients seen in clinical practice. Similarly, although patients (IGT-diabetes population) were identified as having or not having diabetes, this was based on medical history (and not on specific tests performed at the time of enrollment), and, therefore, the diagnosis was unclear. However, patients with elevated blood glucose also have an increased risk of diabetes and diabetes-associated diseases [41]. Furthermore, there was no assessment of diabetes control $\left(\mathrm{HbA}_{1 \mathrm{c}}\right)$ at baseline, and it is possible that patients with well-controlled diabetes might have exhibited different results from those with unstable glycemia (although it should be noted that patients with $\mathrm{HbA}_{1 \mathrm{c}}$ $>10 \%$ were excluded from CAPACITY). Incidentally, due to the limited data collected, it was not possible to address other questions of interest (for example, whether there was evidence for a link between diabetes and IPF). Additionally, some patients had received metformin treatment for a very limited duration at the time a baseline history was taken and, therefore, may not have derived the full benefit of treatment. Moreover, as mechanistic linkage between metformin and IPF disease progression cannot be determined, it remains uncertain whether metformin might also have harmful effects on patients with IPF. It is possible, for example, that metformin may impact directly on lung fibrosis or have an interaction with antifibrotics. With regard to this particular study, it should also be noted that diabetic patients in the nonmetformin users group were being treated with different antidiabetic medications, and it is possible that the effects of metformin on disease progression through improvement of glucose metabolism may have been diluted by other antidiabetic medications. Furthermore, patients may have been taking medications that had a positive effect on outcomes, such as statins, which may be more commonly used in 
patients with diabetes compared with nondiabetic patients [42]. Finally, a minority of patients had prior use of acetylcysteine, which could have had an effect on outcomes; however, the data are insufficient to investigate a systematic effect of acetylcysteine use for metformin users versus nonmetformin users.

In conclusion, this post hoc analysis found that patients with IPF with baseline metformin use had comparable clinical outcomes with patients who did not have baseline metformin use, irrespective of the presence of a history of comorbid diabetes. This finding was also observed when patients with IPF who received antifibrotic therapy were included. Our results suggest that metformin may have no effect on clinically relevant outcomes in patients with IPF; however, this study had various limitations which could have impacted on the results. Further research is needed to understand the role of diabetes in IPF and any potential impact of the comorbidity and its treatment on IPF disease outcomes.

\section{Acknowledgments}

Medical writing support was provided by Gráinne Faherty and Marianne Wells on behalf of CMC AFFINITY, a division of Complete Medical Communications, Ltd., Glasgow, UK, funded by F. Hoffmann-La Roche, Ltd.

\section{Disclosure Statement}

P. Spagnolo has received personal fees from F. Hoffmann-La Roche, Ltd., Boehringer Ingelheim, Zambon, Galapagos, and PPM Services S.A.

M. Kreuter has received grants and personal fees from Boehringer Ingelheim, and grants and personal fees from F. HoffmannLa Roche, Ltd.

T.M. Maher has received industry-academic research funding from GlaxoSmithKline R\&D, UCB, and Novartis, and has received consultancy or speaker's fees from AstraZeneca, Bayer, Biogen Idec, Boehringer Ingelheim, Cipla, Dosa, Galapagos, GlaxoSmithKline R\&D, ProMetic Life Sciences Inc., Roche (and previously InterMune), Sanofi, Takeda, and UCB.

W. Wuyts has received research grants from InterMune/Roche and personal fees from Bayer, Boehringer Ingelheim, and F. Hoffmann-La Roche, Ltd.

F. Bonella has received grants and personal fees from Boehringer Ingelheim and F. Hoffmann-La Roche, Ltd., and grants from Savara Pharma.

T.J. Corte has received grants and personal fees from Boehringer Ingelheim and F. Hoffmann-La Roche, Ltd., grants from Bayer, BMS, MedImmune, and Sanofi, and personal fees from AstraZeneca.

$\mathrm{S}$. Kopf has received grants from the Federal Ministry for Research $(\mathrm{BMBF}) /$ Center for Diabetes Research (DZD e.V) outside of this submitted work.

D. Weycker is employed by Policy Analysis Inc. (PAI), which received funding for this research from F. Hoffmann-La Roche, Ltd.

K.-U. Kirchgaessler is an employee of Roche-Genentech and holds F. Hoffmann-La Roche, Ltd. shares.

C.J. Ryerson has received grants and personal fees from Boehringer Ingelheim, grants and personal fees from F. Hoffmann-La Roche, Ltd., personal fees from Global Blood Therapeutics, and personal fees from ProMetic Life Sciences Inc.

\section{Funding Sources}

This study was sponsored by F. Hoffmann-La Roche, Ltd. Professor Paolo Spagnolo is supported by the grant BIRD163522 from the Department of Cardiac, Thoracic and Vascular Sciences, University of Padova (Padova, Italy). Professor Toby M. Maher is supported by an NIHR Clinician Scientist Fellowship (NIHR Ref: CS-2013-13-017).

\section{Author Contributions}

All authors were involved in the design of this analysis and the interpretation of results, contributed to the manuscript from the outset, and read and approved the final draft. All authors vouch for the accuracy of the content included in the final manuscript.

\section{References}

1 Ley B, Collard HR, King TE Jr: Clinical course and prediction of survival in idiopathic pulmonary fibrosis. Am J Respir Crit Care Med 2011;183:431-440.

2 Raghu G, Collard HR, Egan JJ, Martinez FJ, Behr J, Brown KK, Colby TV, Cordier JF, Flaherty KR, Lasky JA, Lynch DA, Ryu JH, Swigris JJ, Wells AU, Ancochea J, Bouros D, Carvalho C, Costabel U, Ebina M, Hansell DM, Johkoh T, Kim DS, King TE Jr, Kondoh Y, Myers J, Müller NL, Nicholson AG, Richeldi L, Selman M, Dudden RF, Griss BS, Protzko SL, Schünemann HJ; ATS/ERS/JRS/ALAT
Committee on Idiopathic Pulmonary Fibrosis: An official ATS/ERS/JRS/ALAT statement: idiopathic pulmonary fibrosis: evidence-based guidelines for diagnosis and management. Am J Respir Crit Care Med 2011;183:788-824.

3 Nathan SD, Shlobin OA, Weir N, Ahmad S, Kaldjob JM, Battle E, Sheridan MJ, du Bois RM: Long-term course and prognosis of idiopathic pulmonary fibrosis in the new millennium. Chest 2011;140:221-229.

4 Kreuter M, Swigris J, Pittrow D, Geier S, Klotsche J, Prasse A, Wirtz H, Koschel D, And- reas S, Claussen M, Grohé C, Wilkens H, Hagmeyer L, Skowasch D, Meyer JF, Kirschner J, Gläser S, Herth FJF, Welte T, Neurohr C Schwaiblmair M, Held M, Bahmer T, Frankenberger M, Behr J: Health related quality of life in patients with idiopathic pulmonary fibrosis in clinical practice: insights-IPF registry. Respir Res 2017;18:139.

5 Russell AM, Ripamonti E, Vancheri C: Qualitative European survey of patients with idiopathic pulmonary fibrosis: patients' perspectives of the disease and treatment. BMC Pulm Med 2016;16:10. 
6 van Manen MJ, Birring SS, Vancheri C, Cottin V, Renzoni EA, Russell AM, Wijsenbeek MS: Cough in idiopathic pulmonary fibrosis. Eur Respir Rev 2016;25:278-286.

7 King TE Jr, Bradford WZ, Castro-Bernardini S, Fagan EA, Glaspole I, Glassberg MK, Gorina E, Hopkins PM, Kardatzke D, Lancaster L, Lederer DJ, Nathan SD, Pereira CA, Sahn SA, Sussman R, Swigris JJ, Noble PW; ASCEND Study Group: A phase 3 trial of pirfenidone in patients with idiopathic pulmonary fibrosis. N Engl J Med 2014;370:2083-2092.

8 Noble PW, Albera C, Bradford WZ, Costabel U, Glassberg MK, Kardatzke D, King TE Jr, Lancaster L, Sahn SA, Szwarcberg J, Valeyre D, du Bois RM; CAPACITY Study Group: Pirfenidone in patients with idiopathic pulmonary fibrosis (CAPACITY): two randomised trials. Lancet 2011;377:1760-1769.

9 Richeldi L, du Bois RM, Raghu G, Azuma A, Brown KK, Costabel U, Cottin V, Flaherty KR, Hansell DM, Inoue Y, Kim DS, Kolb M, Nicholson AG, Noble PW, Selman M, Taniguchi H, Brun M, Le Maulf F, Girard M, Stowasser S, Schlenker-Herceg R, Disse B, Collard HR; INPULSIS Trial Investigators: Efficacy and safety of nintedanib in idiopathic pulmonary fibrosis. N Engl J Med 2014;370 2071-2082.

10 European Medicines Agency: Summary of Product Characteristics - Ofev (nintedanib). http://www.ema.europa.eu/docs/en_GB/ document_library/EPAR_-_Product_Information/human/003821/WC500182474.pdf (last update 2017; accessed January 30, 2018).

11 European Medicines Agency: Summary of Product Characteristics - Esbriet (pirfenidone). http://www.ema.europa.eu/docs/en GB/document_library/EPAR___Product_Information/human/002154/WC500103049. pdf (last update 2017; accessed January 31, 2018).

12 Food and Drug Administration: Highlights of Prescribing Information Ofev. https://www. accessdata.fda.gov/drugsatfda_docs/ label/2017/205832s004lbl.pdf (last update 2017; accessed January 30, 2018).

13 Food and Drug Administration: Highlights of Prescribing Information Esbriet. https:// www.accessdata.fda.gov/drugsatfda_docs/ label/2017/208780s000lbl.pdf (last update 2017; accessed January 30, 2018).

14 Jones MG, Richeldi L: Recent advances and future needs in interstitial lung diseases. Semin Respir Crit Care Med 2016;37:477-484.

15 Kreuter M, Ehlers-Tenenbaum S, Palmowski K, Bruhwyler J, Oltmanns U, Muley T, Heussel CP, Warth A, Kolb M, Herth FJF: Impact of comorbidities on mortality in patients with idiopathic pulmonary fibrosis. PLoS One 2016;11:e0151425.
16 Kim YJ, Park JW, Kyung SY, Lee SP, Chung MP, Kim YH, Lee JH, Kim YC, Ryu JS, Lee HL, Park CS, Uh ST, Lee YC, Kim KH, Chun YJ, Park YB, Kim DS, Jegal Y, Lee JH, Park MS, Jeong SH: Clinical characteristics of idiopathic pulmonary fibrosis patients with diabetes mellitus: the national survey in Korea from 2003 to 2007. J Korean Med Sci 2012;27: 756-760.

17 Enomoto T, Usuki J, Azuma A, Nakagawa T, Kudoh S: Diabetes mellitus may increase risk for idiopathic pulmonary fibrosis. Chest 2003;123:2007-2011.

$18 \mathrm{Hu}$ Y, Ma Z, Guo Z, Zhao F, Wang Y, Cai L, Yang J: Type 1 diabetes mellitus is an independent risk factor for pulmonary fibrosis. Cell Biochem Biophys 2014;70:13851391.

19 Gribbin J, Hubbard R, Smith C: Role of diabetes mellitus and gastro-oesophageal reflux in the aetiology of idiopathic pulmonary fibrosis. Respir Med 2009;103:927-931.

20 American Thoracic Society: Idiopathic pulmonary fibrosis: diagnosis and treatment. International consensus statement. Am J Respir Crit Care Med 2000;161:646-664.

21 Zhao YD, Yin L, Archer S, Lu C, Zhao G, Yao Y, Wu L, Hsin M, Waddell TK, Keshavjee S, Granton J, de Perrot M: Metabolic heterogeneity of idiopathic pulmonary fibrosis: a metabolomic study. BMJ Open Respir Res 2017; 4:e000183.

22 Tsaknis G, Siempos II, Kopterides P, Maniatis NA, Magkou C, Kardara M, Panoutsou S, Kotanidou A, Roussos C, Armaganidis A: Metformin attenuates ventilator-induced lung injury. Crit Care 2012;16:R134.

23 Park CS, Bang BR, Kwon HS, Moon KA, Kim TB, Lee KY, Moon HB, Cho YS: Metformin reduces airway inflammation and remodeling via activation of AMP-activated protein kinase. Biochem Pharmacol 2012;84:16601670.

24 Li L, Huang W, Li K, Zhang K, Lin C, Han R, Lu C, Wang Y, Chen H, Sun F, He Y: Metformin attenuates gefitinib-induced exacerbation of pulmonary fibrosis by inhibition of TGF- $\beta$ signaling pathway. Oncotarget 2015;6: 43605-43619.

25 Lu J, Shi J, Li M, Gui B, Fu R, Yao G, Duan Z, Lv Z, Yang Y, Chen Z, Jia L, Tian L: Activation of AMPK by metformin inhibits TGF- $\beta$ induced collagen production in mouse renal fibroblasts. Life Sci 2015;127:59-65.

26 Sato N, Takasaka N, Yoshida M, Tsubouchi K, Minagawa S, Araya J, Saito N, Fujita Y, Kurita $\mathrm{Y}$, Kobayashi $\mathrm{K}$, Ito $\mathrm{S}$, Hara $\mathrm{H}$, Kadota $\mathrm{T}$, Yanagisawa $\mathrm{H}$, Hashimoto $M$, Utsumi $\mathrm{H}$, Wakui H, Kojima J, Numata T, Kaneko Y, Odaka M, Morikawa T, Nakayama K, Kohrogi $\mathrm{H}$, Kuwano K: Metformin attenuates lung fibrosis development via NOX4 suppression. Respir Res 2016;17:107.

27 Rangarajan S, Locy M, Luckhardt T, Thannickal VJ: Targeted therapy for idiopathic pulmonary fibrosis: where to now? Drugs 2016;76:291-300
28 American Diabetes Association: Diagnosis and classification of diabetes mellitus. Diabetes Care 2007;30:42-47.

29 Allison PD: Survival Analysis Using SAS: A Practical Guide, ed 2. North Carolina, SAS Institute Inc., 2010.

30 Pencina MJ, D'Agostino RB Sr, D'Agostino RB Jr, Vasan RS: Evaluating the added predictive ability of a new marker: from area under the ROC curve to reclassification and beyond. Stat Med 2008;27:157-172.

31 Innocenti F, Fabbri A, Anichini R, Tuci S, Pettinà G, Vannucci F, De Giorgio LA, Seghieri G: Indications of reduced pulmonary function in type 1 (insulin-dependent) diabetes mellitus. Diabetes Res Clin Pract 1994;25: 161-168.

32 Klein OL, Kalhan R, Williams MV, Tipping M, Lee J, Peng J, Smith LJ: Lung spirometry parameters and diffusion capacity are decreased in patients with Type 2 diabetes. Diabet Med 2012;29:212-219.

33 Hyldgaard C, Hilberg O, Bendstrup E: How does comorbidity influence survival in idiopathic pulmonary fibrosis? Respir Med 2014; 108:647-653.

34 Wang J, Wang Y, Han J, Mei H, Yu D, Ding Q, Zhang T, Wu G, Peng G, Lin Z: Metformin attenuates radiation-induced pulmonary fibrosis in a murine model. Radiat Res 2017; 188:105-113.

35 Choi SM, Jang AH, Kim H, Lee KH, Kim YW Metformin reduces bleomycin-induced pulmonary fibrosis in mice. J Korean Med Sci 2016;31:1419-1425.

36 Burkewitz K, Zhang Y, Mair W: AMPK at the nexus of energetics and aging. Cell Metab 2014;20:10-25.

37 Mihaylova M, Shaw RJ: The AMP-activated protein kinase (AMPK) signaling pathway coordinates cell growth, autophagy, and metabolism. Nat Cell Biol 2011;13:1016-1023.

38 Araya J, Kojima J, Takasaka N, Ito S: Insufficient autophagy in idiopathic pulmonary fibrosis. Am J Physiol Lung Cell Mol Physiol 2013;304:L56-L69.

39 Patel AS, Lin L, Geyer A, Haspel J: Autophagy in idiopathic pulmonary fibrosis. PLoS One 2012;7:e41394.

40 Viollet B, Guigas B, Sanz Garcia N, Leclerc J, Foretz M, Andreelli F: Cellular and molecular mechanisms of metformin: an overview. Clin Sci (Lond) 2012;122:253-270.

41 Barr EL, Zimmet PZ, Welborn TA, Jolley D, Magliano DJ, Dunstan DW, Cameron AJ, Dwyer T, Taylor HR, Tonkin AM, Wong TY, McNeil J, Shaw JE: Risk of cardiovascular and all-cause mortality in individuals with diabetes mellitus, impaired fasting glucose, and impaired glucose tolerance: the Australian Diabetes, Obesity, and Lifestyle Study (AusDiab). Circulation 2007;116:151-157.

42 Kreuter M, Bonella F, Maher TM, Costabel U, Spagnolo P, Weycker D, Kirchgaessler KU, Kolb M: Effect of statins on disease-related outcomes in patients with idiopathic pulmonary fibrosis. Thorax 2017;72:148-153. 